\title{
Parameter Influences of Light Floating Slab on Its Vertical Vibration Excited by Track Irregularity
}

\author{
Guangtian Shi ${ }^{*}$, , Jianjin Yang ${ }^{1}$ and Xinwen Yang ${ }^{2}$

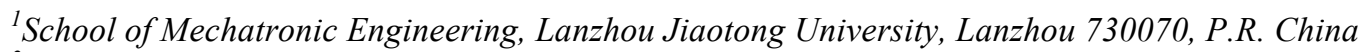 \\ ${ }^{2}$ School of Transportation Engineering, Tongji University, Shanghai 201804, P.R. China
}

\begin{abstract}
According to the structure characteristics of railway viaduct with light floating slabs, a frequency domain dynamic model of the vehicle-light floating slab track-viaduct bridge vertical coupling system is established. The Green functions are used to quickly calculate the receptance response of the system, and then the pseudo excitation method is used to further analyze the parameter influences of the floating slab on the vertical vibration excited by the track irregularity. The parameters of the floating slab have obvious effects on its vertical vibration, so as we strive to reduce the vibration and noise radiation of the railway by changing the parameters of the floating slab, the disadvantages to the vibration and noise control of the floating slab have to be taken into consideration.
\end{abstract}

Keywords: Coupling vibration, green functions, light floating slab track, parameter influences, pseudo excitation method, urban railway.

\section{INTRODUCTION}

The urban railway has been receiving various applications at many transit systems, due to large capacity, punctuality, fast speed and high efficiency. However, there are also some problems, for example, vibration and noise pollution. So measures should be adopted to reduce the adverse factors. From the time the floating slab track was first used in Germany in 1965, its outstanding performance of vibration isolation has been observed. Now, the floating slab track has been widely used in the urban railway and many scholars have conducted a lot of researches on it.

Nelson introduced two kinds of floating slab track systems of the prefabricated type and cast-in-place type and studied their engineering application and effects on vibration isolation [1]. Hussein and Hunt studied the responses for a track with discontinuous slab to oscillating moving loads and then discussed its response to moving trains. They also developed a numerical model for calculating vibration due to a harmonic moving load on a floating slab track with discontinuous slabs in an underground railway tunnel [2-4]. In addition, Gupta and Degrande presented a periodic approach to couple a track with discontinuous or continuous slab and a tunnel-soil system of different periodicity [5]. Cui and Chew investigated the effectiveness of a floating slab track system to stationary harmonic loads and moving harmonic loads using the receptance method [6]. $\mathrm{Li}$ and $\mathrm{Wu}$ discussed parametric excitation vibration of a floating slab track and used the dynamic receptance method to study the performance of vibration isolation of a floating slab track [7, $8]$.

The floating slab track also has an important effect on the control of ground-borne vibrations generated by rail

*Address correspondence to this author at the School of Mechatronic Engineering, Lanzhou Jiaotong University, Lanzhou 730070, P.R. China; Tel: +86-931-4938013; Fax: +86-931-4938023; E-mail: shigt@mail.lzjtu.cn transportation systems. Lombaert and Degrande et al. studied the effectiveness of the floating slab track by means of a three-dimensional numerical model for the prediction of railway induced vibrations that fully account for the interaction between the train, the track and the soil [9]. Cox and Wang et al. used a large constructed test rig based on three $2.5 \mathrm{~m}$ long full-scale floating track slab elements to investigate slab track structures for controlling ground vibration [10]. Auersch and Eng analyzed the dynamics of slab tracks and floating slab tracks by multi-beam models for the track and by integration in the wave-number domain for the soil, which is modeled as a layered half-space [11].

In recent years, the floating slab track has been used in railway viaduct. Hui and $\mathrm{Ng}$ studied the effects of floating slab bending resonances on the vibration isolation of railway viaduct, and they found that the bending resonances of slabs have significant effects on vibration isolation performance [12]. But they did not discuss the parameter influences of floating slab on its own vibrations.

The existing researches are mainly concerned about the floating slab track system in the underground railway tunnel and are focused on the dynamics of slab track and its controls of the environmental vibration and noise radiation along railway lines. However, the light floating slab is also an important source of noise in the railway viaduct. There are few research articles on the parameter influences of the floating slab on its vibration and noise radiation in detail which is also the focus of investigation in this paper.

In this paper, according to the structure characteristics of railway viaduct with light floating slabs (as shown in Fig. 1), a frequency domain dynamic model of the vehicle-light floating slab track-viaduct bridge vertical coupling system was first developed. It is not easy to decouple the coupling system and calculate the vertical wheel/rail force excited by the track and rail irregularities fast and efficiently. However, the Green functions and pseudo excitation method can solve 
these problems. So Green functions are used to quickly calculate the receptance response of the system. Finally, the parameter influences of floating slab on its own vibrations excited by the track irregularity spectrum are discussed in detail, although few research articles are available on the subject. The results illustrate the parameters influences of the light floating slab on its vertical vibration excited by the irregularities. And in our further researches, the focus will be on the control of the noise radiated by the floating slab. So this paper will lay the foundation for our next studies.

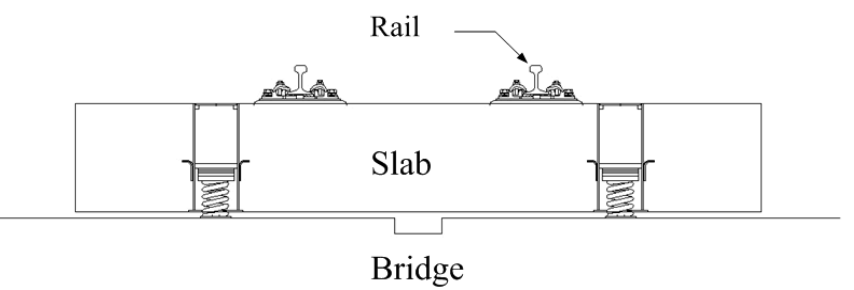

Fig. (1). The railway viaduct with light floating slab.

\section{THEORETICAL MODEL}

\subsection{Physical Model}

Based on the vehicle-track-bridge coupling dynamics theory, and according to the structural characteristics of railway viaduct with light floating slabs, the vehicle-floating slab track-viaduct bridge vertical coupling dynamic model is established, as shown in Fig. (2).

The vehicle is the A type vehicle used in Shanghai urban railway. The parameters for the railway viaduct with light floating slabs are listed in Table $\mathbf{1 .}$

In the model, the floating slab track subsystem is composed of rails, fasteners, floating slab and steel springs, and the viaduct bridge subsystem is composed of viaduct bridge and bridge supports. It is assumed that the ends of the bridge supports connected to the piers are fixed. The rails are represented by infinite Timoshenko beams. The slab and bridge are modeled as a free-free Euler beam and a simply supported Euler beam, respectively. The fasteners, steel springs and bridge supports are modeled to be spring-damper elements.

\subsection{Equations of Motion of the Railway Viaduct}

The Rail is presented by an infinite Timoshenko beam, so its Green function is [13].

$$
G_{r}\left(x_{1}, x_{2}\right)=u_{1} e^{-\mathrm{i} k_{1}\left|x_{1}-x_{2}\right|}+u_{2} e^{-k_{2}\left|x_{1}-x_{2}\right|}
$$

where

$$
\begin{aligned}
& k_{1,2}=\left(\frac{\omega}{\sqrt{2}}\right)\left\{\begin{array}{l} 
\pm\left(\frac{\rho_{r}}{E_{r}\left(1+\eta_{r}\right)}+\frac{\rho_{r}}{G_{r}{ }_{r}}\right)+ \\
{\left[\left(\frac{\rho_{r}}{E_{r}\left(1+\eta_{r}\right)}-\frac{\rho_{r}}{G_{r}{ }_{r}}\right)^{2}+\frac{4 \rho_{r} A_{r}}{E_{r}\left(1+\eta_{r}\right) I_{r} \omega^{2}}\right]^{1 / 2}}
\end{array}\right\}^{1 / 2} \\
& u_{1}=\frac{\mathrm{i}}{E_{r}\left(1+\eta_{r}\right) I_{r} G_{r} \kappa_{r}} \frac{\rho_{r} I_{r} \omega^{2}-G_{r} \kappa_{r} A_{r}-E_{r}\left(1+\eta_{r}\right) I_{r} k_{1}^{2}}{2 A_{r} k_{1}\left(k_{1}^{2}+k_{2}^{2}\right)} \\
& u_{2}=\frac{1}{E_{r}\left(1+\eta_{r}\right) I_{r} G_{r} \kappa_{r}} \frac{\rho_{r} I_{r} \omega^{2}-G_{r} \kappa_{r} A_{r}+E_{r}\left(1+\eta_{r}\right) I_{r} k_{2}^{2}}{2 A_{r} k_{2}\left(k_{1}^{2}+k_{2}^{2}\right)}
\end{aligned}
$$

$G_{r}\left(x_{1}, x_{2}\right)$ is the response of a Timoshenko beam (at any observer point $x_{l}$ on the beam) to a unit point force (acting at $x_{2}$ ), and $\omega$ is the angular frequency.

The floating slab can be simplified as free-free Euler beam, and its Green function, in modal superposition form

Table 1. Parameters used in the model.

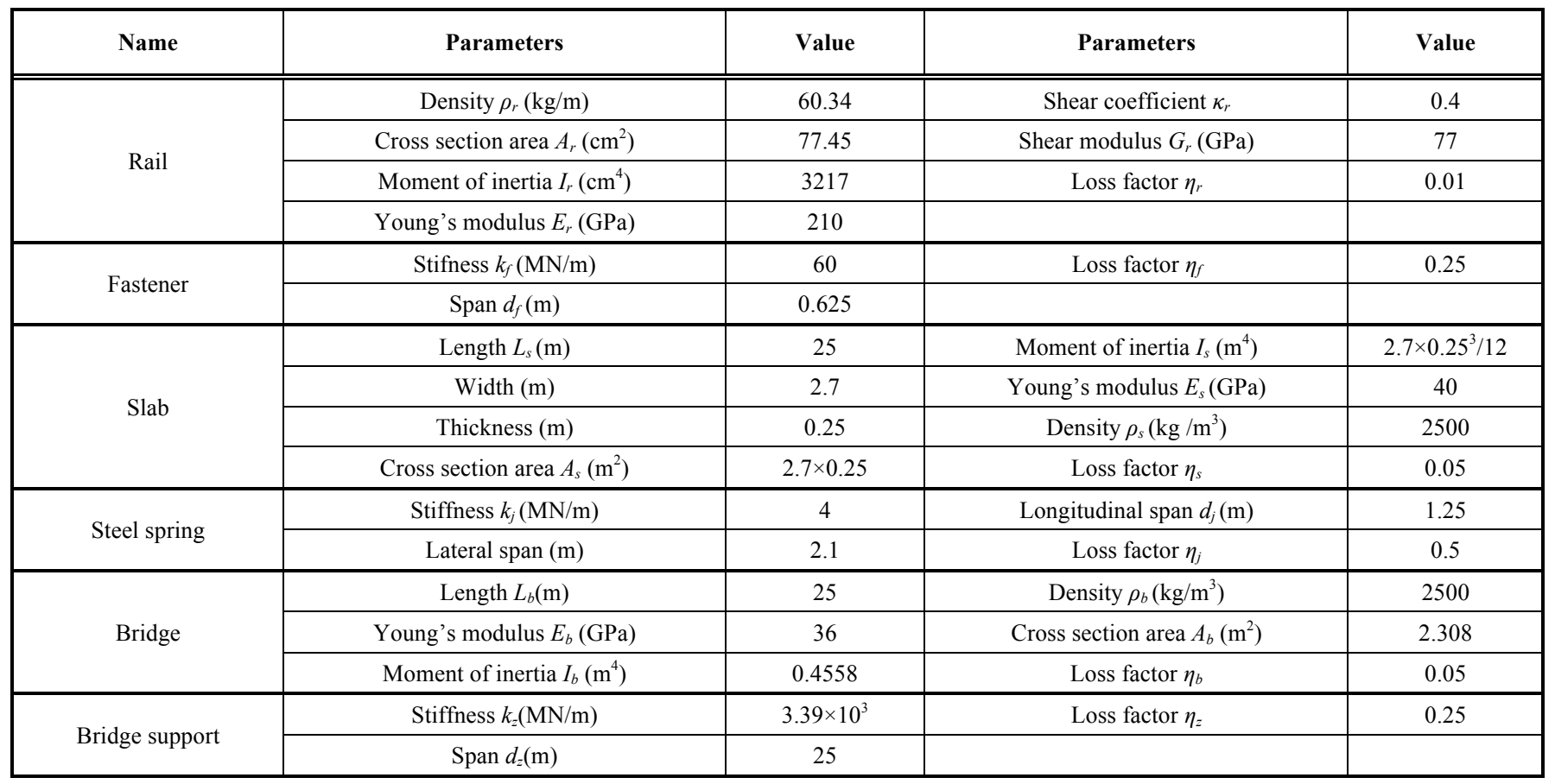




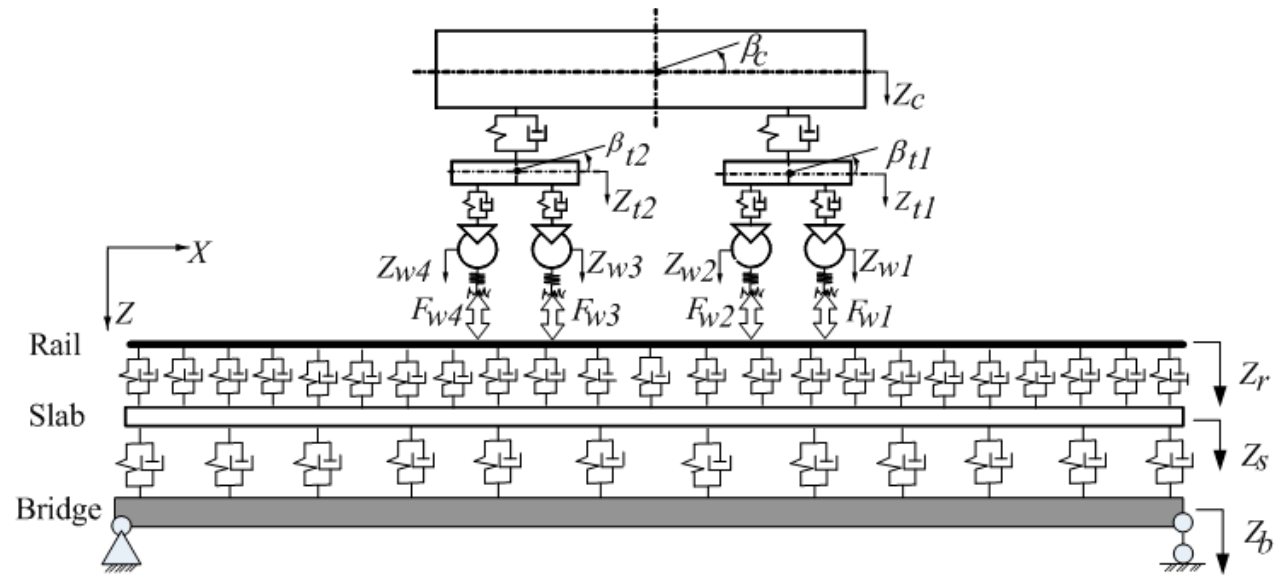

Fig. (2). The light floating slab track-viaduct bridge vertical coupling dynamic model.

[14], can be written as:

$$
u_{2}=\frac{1}{E_{r}\left(1+\eta_{r}\right) I_{r} G_{r} \kappa_{r}} \frac{\rho_{r} I_{r} \omega^{2}-G_{r} \kappa_{r} A_{r}+E_{r}\left(1+\eta_{r}\right) I_{r} k_{2}^{2}}{2 A_{r} k_{2}\left(k_{1}^{2}+k_{2}^{2}\right)}
$$

where, $W_{s n}(x)$ is the $n$th modal shape function of the free-free Euler beam, and the corresponding frequency is $\omega_{s n}=k_{n}^{2} \sqrt{E_{s} I_{s} / \rho_{s} A_{s}} . N M S$ is the modal number of floating slab for calculation. The expression for $W_{s n}(x)$ is as shown in formula (4).

$$
\left\{\begin{array}{l}
W_{s 1}(x)=\frac{1}{\sqrt{\rho_{s} A_{s} L_{s}}} \\
W_{s 2}(x)=\frac{1}{\sqrt{\rho_{s} A_{s} L_{s}}} \sqrt{3}\left(1-2 x / L_{s}\right), \quad 0 \leq z \leq L_{s} \\
W_{s n}(x)=\frac{1}{\sqrt{\rho_{s} A_{s} L_{s}}}\left[\begin{array}{l}
\left(\cosh k_{s n} x+\cos k_{s n} x\right)- \\
c_{n}\left(\sinh k_{s n} x+\sin k_{s n} x\right)
\end{array}\right], \quad n \geq 3
\end{array}\right.
$$

The first two modal shape functions correspond to the rigid motion of Euler beam, and the other modal shape functions correspond to the bend motion of Euler beam. The values of $k_{s n}$ and $c_{n}$ are referenced in [14].

The viaduct bridge is regarded as a simply supported Euler beam. Its steady-state response can also be expressed in modal superposition form [15]. Its Green function is

$G_{b}\left(x_{2}, x_{1}\right)=\sum_{n=1}^{N M B} \frac{W_{b n}\left(x_{2}\right) W_{b n}\left(x_{1}\right)}{\left(1+\mathrm{i} \eta_{b}\right) \omega_{b n}^{2}-\omega^{2}}$

where, $W_{b n}(x)$ is the $n$th modal shape function of the simply supported Euler beam, and the corresponding frequency is $\omega_{b n}=k_{b n}^{2} \sqrt{E_{b} I_{b} / \rho_{b} A_{b}}, k_{b n}=n \pi / L_{b} . N M B$ is the modal number of viaduct bridge for calculation. Using the classic normal modals of simply supported Euler beam, the expression of $W_{b n}(x)$ can be obtained as follows:

$W_{b n}(x)=\sqrt{2 /\left(\rho_{b} A_{b} L_{b}\right)} \sin \left(n \pi x / L_{b}\right)$

Using the implication of Green function and the superposition principle, the equation of motion of the rail in frequency domain can be obtained which is written as follows:

$$
\begin{aligned}
u_{r}(x)= & \sum_{a=1}^{A} G_{r}\left(x_{a}, x\right) F_{w a} \\
& -\sum_{n=1}^{N} G_{r}\left(x_{n}, x\right) K_{f}\left(u_{r}\left(x_{n}\right)-u_{s}\left(x_{n}\right)\right)
\end{aligned}
$$

The equation of motion of the floating slab in frequency domain is

$$
\begin{aligned}
u_{s}(x)= & \sum_{n=1}^{N} G_{s}\left(x_{n}, x\right) K_{f}\left(u_{r}\left(x_{n}\right)-u_{s}\left(x_{n}\right)\right) \\
& -\sum_{m=1}^{M} G_{s}\left(x_{m}, x\right) K_{j}\left(u_{s}\left(x_{m}\right)-u_{b}\left(x_{m}\right)\right)
\end{aligned}
$$

The equation of motion of the viaduct bridge in frequency domain is

$$
\begin{aligned}
u_{b}(x)= & \sum_{m=1}^{M} G_{b}\left(x_{m}, x\right) K_{j}\left(u_{s}\left(x_{m}\right)-u_{b}\left(x_{m}\right)\right) \\
& -\sum_{z=1}^{Z} G_{b}\left(x_{z}, x\right) K_{z} u_{b}\left(x_{z}\right)
\end{aligned}
$$

where

$$
K_{f}=k_{f}\left(1+\mathrm{i} \eta_{f}\right), K_{j}=k_{j}\left(1+\mathrm{i} \eta_{j}\right), K_{z}=k_{z}\left(1+\mathrm{i} \eta_{z}\right)
$$

and $F_{w a}$ is the vertical excitation force applied at $x_{a}$ by the $a$ th wheel; $x_{n}, x_{m}$ and $x_{z}$ are the positions of the $n$th fastener, the $m$ th steel spring and the $z$ th bridge support in the direction of $x$ in Fig. (2).

Using formulas (7), (8) and (9), the equations of motion of the railway viaduct in the matrix form can be obtained as:

$$
[G K]\{u\}=\{F\}
$$

where, $[G K]$ is a square matrix with its elements composed of zeros and Green functions of the rail, slab and viaduct bridge multiplying $K_{f}, K_{j}$ and $K_{z} .\{u\}$ is the vertical displacement vector of the rail, slab and viaduct bridge. $\{F\}$ is the force vector composed of zeros and the force 
multiplying the Green function of the rail. If a unit force is acting on the point $x$ on the rail, the obtained vibration response of the rail at the point $x$ is also called the point receptance function of the track $\left[\alpha_{T}\right]$.

\subsection{Equations of Motion of the Vehicle}

The differential equation of motion of the vehicle is

$$
\left\{U_{\mathrm{v}}(\omega)\right\}=\frac{\left\{F_{w a}(\omega)\right\}}{\omega^{2}\left[M_{V}\right]-\mathrm{i} \omega\left[C_{V}\right]+\left[K_{V}\right]}
$$

where $\left[M_{V}\right],\left[C_{V}\right]$ and $\left[K_{V}\right]$ are the mass matrix, damping matrix and stiffness matrix of the vehicle, respectively, $\left\{U_{V}(\omega)\right\}$ is the displacement amplitude vector of the vehicle, $\left\{F_{w a}(\omega)\right\}$ is the vector of the amplitudes of wheel/rail vertical forces induced by track irregularity and $\omega$ is the angular frequency.

According to the definition of displacement receptance, the receptance of the vehicle can be obtained by formula (12) shown as

$$
\left[\alpha_{V}\right]=\left(\omega^{2}\left[M_{V}\right]-\mathrm{i} \omega\left[C_{V}\right]+\left[K_{V}\right]\right)^{-1}
$$

Then the receptance of the vehicle at the position of the wheel is

$\left[\alpha_{W}\right]=[H]\left[\alpha_{V}\right][H]^{\mathrm{T}}$

\subsection{Wheel/Rail Contact Force}

$\left\{F_{w a}(\omega)\right\}$ can be obtained by formula (15), as follows [16]:

$$
\left\{F_{w a}(\omega)\right\}=\frac{\{\Delta u(\omega)\}}{\left[\alpha_{W}\right]+\left[\alpha_{T}\right]+\left[\alpha_{\Delta}\right]}
$$

where, $\left[\alpha_{4}\right]$ is the receptance of the wheel/rail contact spring, the inverse of the contact stiffness $k_{H}$ whose value is $1.38 \mathrm{MN} / \mathrm{m}$ is calculated by Hertz contact theory. $\{\Delta u(\omega)\}$ is the excitation transformed from the track irregularity by the pseudo excitation method [17]. And the excitation is input using the fixed-point excitation model which assumes that the vehicle and track are fixed and the track irregularity is moving.

It can be assumed that the wheel sets are excited by the same track irregularity with a certain time difference as the train runs on a track. So, there are $N$ stationary random excitations with different phases corresponding to $N$ wheel sets, which can be expressed as:

$$
\begin{aligned}
\{\Delta u(t)\} & =\left\{\begin{array}{llll}
\Delta u_{1}(t) & \Delta u_{2}(t) & \ldots & \Delta u_{N}(t)
\end{array}\right\} \\
& =\left\{\begin{array}{llll}
\Delta u\left(t-t_{1}\right) & \Delta u\left(t-t_{2}\right) & \ldots & \Delta u\left(t-t_{N}\right)
\end{array}\right\}
\end{aligned}
$$

where $\Delta u(t)$ is the time history function of the random excitation of track vertical profile irregularity, $t_{j}=L_{j} / v$ $(\mathrm{j}=1,2, \ldots, N)$ is the lag time of the $j$ th excitation corresponding to its spatial separation, $L_{j}$ and the vehicle speed $v$. Using formula (17), the pseudo excitation corresponding to $\Delta u(t)$ can be obtained which is shown as

$$
\Delta \tilde{u}(t)=\sqrt{S_{v}(\omega)} e^{i \omega t}
$$

where, $S_{v}(\omega)$ is the auto spectral density of $\Delta u(t)$. Then the pseudo excitation corresponding to $\{\Delta u(t)\}$ is

$$
\begin{aligned}
\{\Delta \tilde{u}(t)\} & =\left\{\begin{array}{llll}
\Delta \tilde{u}\left(t-t_{1}\right) & \Delta \tilde{u}\left(t-t_{2}\right) & \cdots & \Delta \tilde{u}\left(t-t_{M}\right)
\end{array}\right\} \\
& =\left\{\begin{array}{llll}
e^{-i \omega t_{1}} & e^{-i \omega t_{2}} & \cdots & e^{-i \omega t_{M}}
\end{array}\right\} \sqrt{S_{v}(\omega)} e^{i \omega t} \\
& =\left\{\begin{array}{lll}
\Delta \tilde{u}(\omega) & e^{i \omega t}
\end{array}\right.
\end{aligned}
$$

where, $\{\Delta \tilde{u}(\omega)\}=\left\{\begin{array}{llll}e^{-i \omega t_{1}} & e^{-i \omega t_{2}} & \cdots & e^{-i \omega t_{M}}\end{array}\right\} \sqrt{S_{v}(\omega)}$ is the amplitude of the harmonic irregularity of the pseudo excitation.

Substituting $\{\Delta \tilde{u}(\omega)\}$ for $\{\Delta u(\omega)\}$ in formula (15) yields

$$
\{\tilde{P}(\omega)\}=\frac{\{\Delta \tilde{u}(\omega)\}}{\left[\alpha_{W}\right]+\left[\alpha_{T}\right]+\left[\alpha_{\Delta}\right]}
$$

where, $\{\tilde{P}(\omega)\}$ is the amplitude of pseudo dynamic wheel/rail force corresponding to $\{\Delta \tilde{u}(\omega)\}$. So by solving formula (19), the amplitude of pseudo dynamic wheel/rail force excited by track irregularity is obtained. Using the definition of pseudo excitation method again, the power spectral density of the dynamic wheel/rail force can be obtained, expressed as

$S_{P P}(\omega)=\{\tilde{P}(\omega)\}^{*} \cdot\{\tilde{P}(\omega)\}^{T}$

where, $\{\tilde{P}(\omega)\}^{*}$ and $\{\tilde{P}(\omega)\}^{T}$ are the conjugate matrix and transposed matrix of $\{\tilde{P}(\omega)\}$, respectively.

Using the power spectral density of the dynamic wheel/rail force and formula (11) and (12), the dynamic responses of the railway viaduct and vehicle excited by the track irregularity can be calculated.

\section{NUMERICAL ANALYSIS AND DISCUSSIONS}

\subsection{Vertical Receptance Characteristics of Railway Viaduct}

To investigate the receptance characteristics of the railway viaduct, a vertical unit force is acted on the rail either at the mid-span of the bridge (above fastener) or at the mid-span of fastener bay closest to the mid-span of the bridge. The vertical vibrations of the points of the rail, floating slab and bridge in the cross section of the force are shown in Figs. $(\mathbf{3}, \mathbf{4})$.

All the vertical displacement receptances of the rail, slab and bridge have peak values at the natural vibration frequencies of the rail-floating slab-viaduct bridge system. So it can be deduced that those natural vibration frequencies have great influences on the vertical vibration of the railway viaduct. Below $80 \mathrm{~Hz}$, the vertical displacement receptances of the rail change are consistent with that of the floating slab, and with the increasing frequency. The vertical displacement receptances of the rail are greater than that of the floating slab, which are also greater than that of the bridge, and the differences between them are more and more pronounced. At 
the first 'pinned-pinned' frequency, the vertical displacement receptances and phases of the rail have troughs for the unit force above fastener and peaks for the unit force at mid-span of fastener bay.

For the phase, it can be found that the phases of the vertical displacement receptances of the rail are negative in the entire frequency range, however, that of the floating slab and bridge are more complex. In addition, the phases of the vertical displacement receptances of the floating slab and bridge induced by the unit force above fastener are more complex. Above $1000 \mathrm{~Hz}$, the unit force above fastener marks the phases of the vertical displacement receptances of the floating slab and bridge obvious shock.

(a)

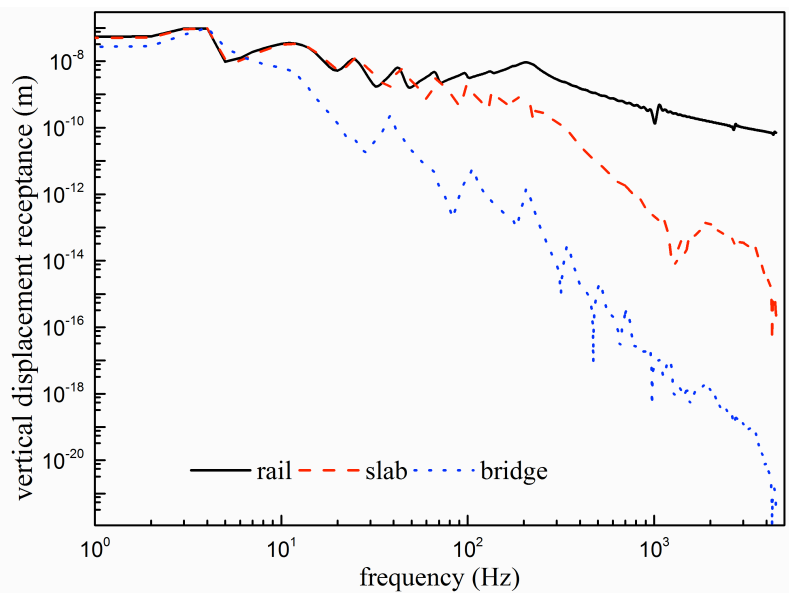

(b)

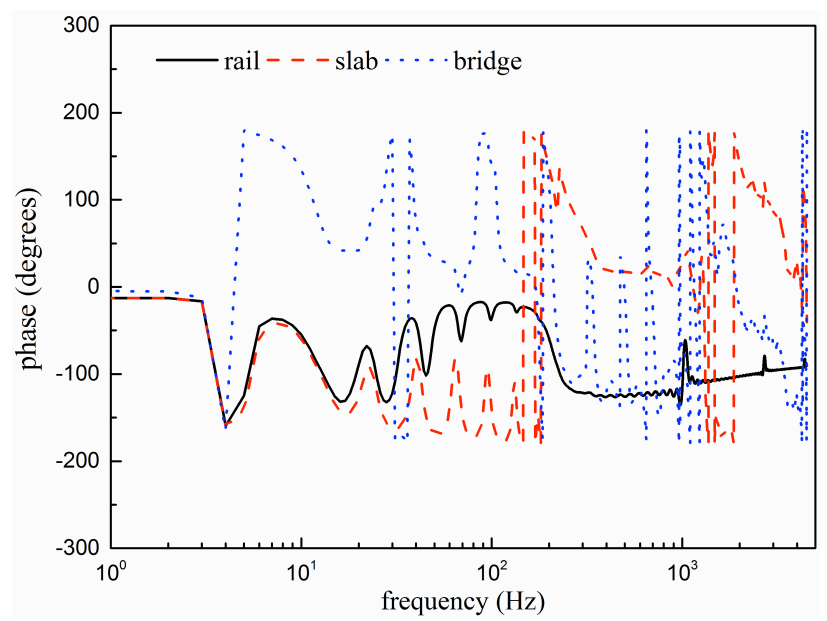

Fig. (3). The vertical receptances to a unit force above fastener, (a) amplitudes and (b) phase.

\subsection{Parameter Influences of Floating Slab on its Vibration}

In this part, the parameter influences of floating slab on its vertical vibrations are discussed, excited by the sixth grade track irregularity PSD of U.S. railways (with wavelength $1 \sim 100 \mathrm{~m}$ ) and the Sato track irregularity (with wavelength $0.01 \sim 1 \mathrm{~m}$ ). In the calculation, the vehicle is the A type vehicle located at the center of a viaduct bridge and its speed is $100 \mathrm{~km} / \mathrm{h}$. The distance between bogie centers is $17.5 \mathrm{~m}$ and wheel base of bogie is $2.5 \mathrm{~m}$. (a)

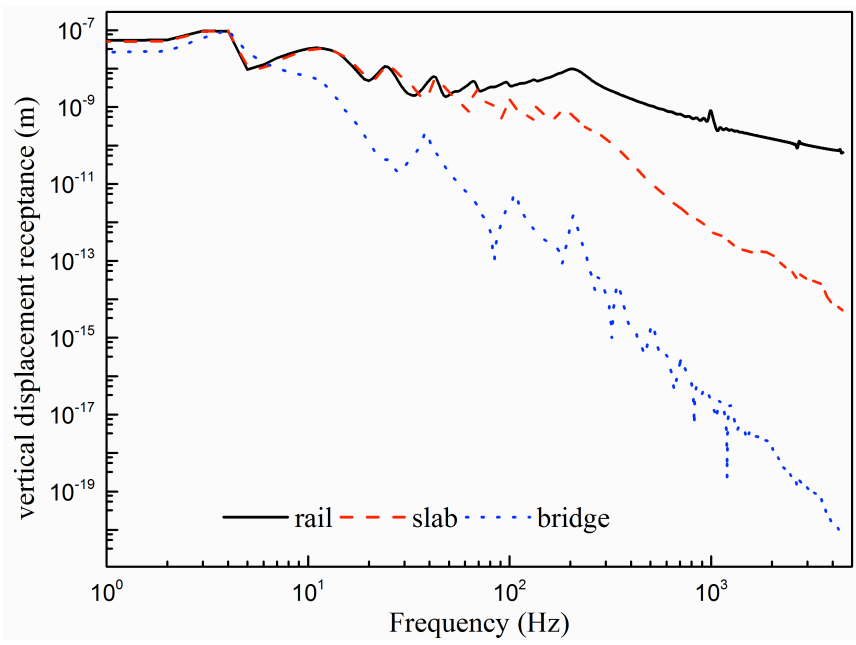

(b)

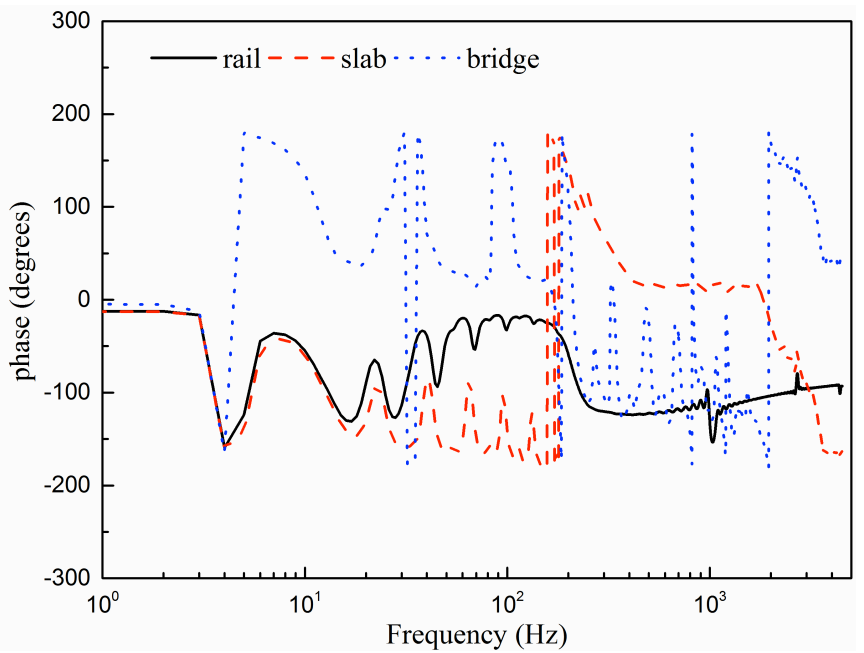

Fig. (4). The vertical receptances to a unit force at mid-span of fastener bay, (a) amplitudes and (b) phase.

In order to illustrate the characteristics of vibration transfer in floating slab track system, the vibration power flow is used here to analyze the vibration transfer and its influence factors. The average vibration power of a structure in frequency domain is expressed as

$$
P(\omega)=\frac{1}{2} \operatorname{Re}\left\{F^{*}(\omega) \cdot V(\omega)\right\}
$$

where, $F^{*}(\omega)$ is the ad joint matrix of the vector of the force amplitude acting on the structure and $V(\omega)$ is the vibration velocity matrix of the structure in frequency domain.

Firstly, the effect of the stiffness of the steel springs on the vertical vibration of the floating slab is discussed. The vertical acceleration power spectrum and the vertical vibration power of the floating slab with the different stiffness of the steel springs $4 \mathrm{MN} / \mathrm{m}, 10 \mathrm{MN} / \mathrm{m}, 15 \mathrm{MN} / \mathrm{m}$ and $20 \mathrm{MN} / \mathrm{m}$ are shown in Fig. (5).

At about $70 \mathrm{~Hz}$, the vertical acceleration power spectrums of the floating slab have sharp peaks with values of $80,41.0$, 25.9 and $18.6\left(\mathrm{~m} / \mathrm{s}^{2}\right)^{2} / \mathrm{Hz}$, decreasing by $48.8 \%, 36.8 \%$ and $28.2 \%$ respectively. The stiffness of the steel springs 
$4 \mathrm{MN} / \mathrm{m}, 10 \mathrm{MN} / \mathrm{m}, 15 \mathrm{MN} / \mathrm{m}$ and $20 \mathrm{MN} / \mathrm{m}$, increases by $150 \%, 50 \%$ and $33.3 \%$ respectively. At other frequencies, the stiffness of the steel springs has a lesser effect on the vertical vibration of the floating slab.

Around $20 \mathrm{~Hz}$, with the stiffness of the steel springs increasing, the vertical vibration power of the floating slab decreases. On the contrary, in the frequency range of about $20 \sim 100 \mathrm{~Hz}$, as the stiffness of the steel springs is greater, the vertical vibration power of the floating slab is also greater. Around $100 \mathrm{~Hz}$, the stiffness of the steel springs hardly affects the vertical vibration power of the floating slab.

(a)

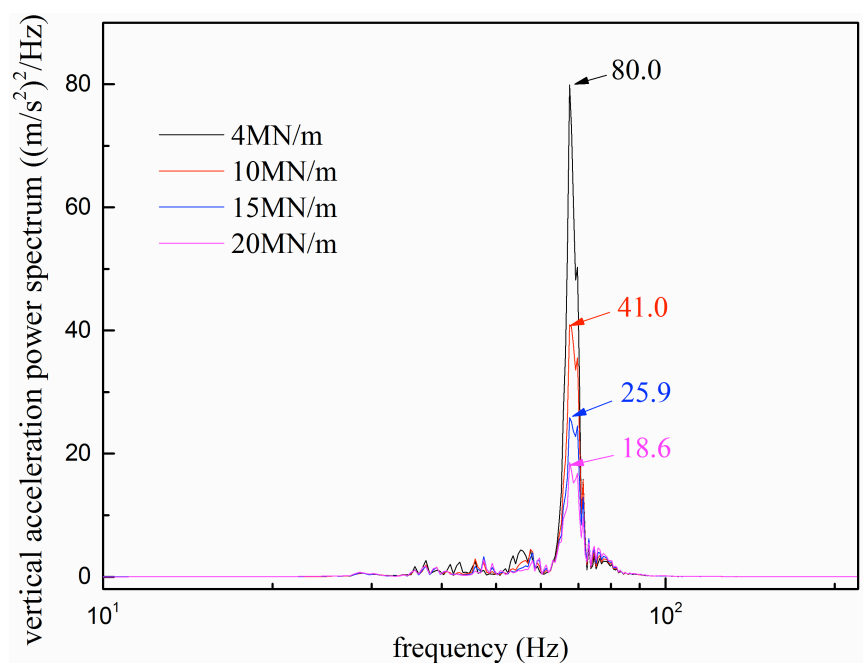

(b)

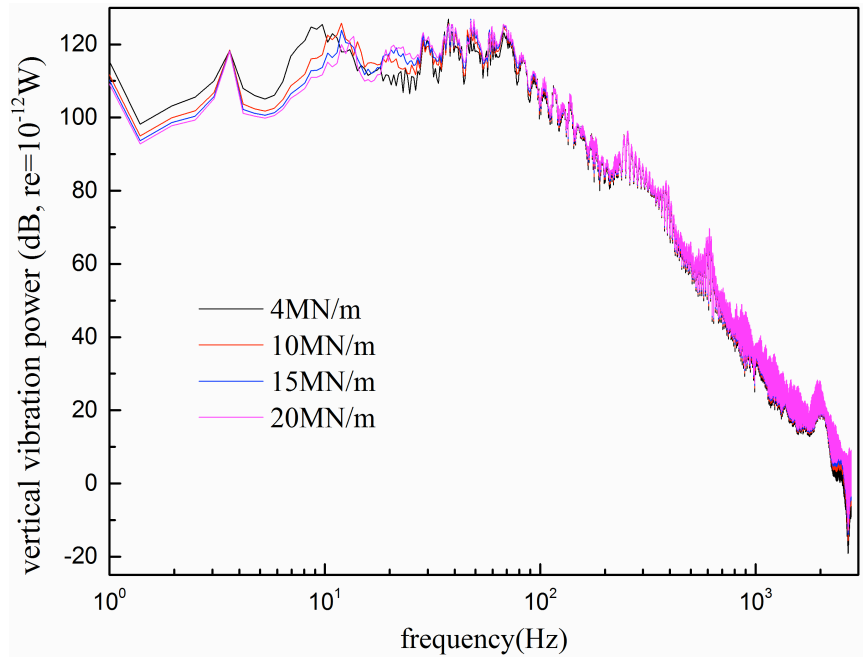

Fig. (5). The effect of stiffness of the steel springs on the vertical vibration of the floating slab.

The vertical acceleration power spectrum and the vertical vibration power of the floating slab with different longitudinal spacing of the steel springs $0.625 \mathrm{~m}, 1.25 \mathrm{~m}$, $1.875 \mathrm{~m}$ and $2.5 \mathrm{~m}$ are shown in Fig. (6).

The influences of the longitudinal spacing increase in the steel springs and the stiffness decrease in the steel springs on the vertical vibration of the floating slab are almost consistent. The values of the sharp peaks of the vertical acceleration power spectrums of the floating slab at about 70 $\mathrm{Hz}$ are 93.4, 90.0, 80.0 and $53.4\left(\mathrm{~m} / \mathrm{s}^{2}\right)^{2} / \mathrm{Hz}$ decreasing by $3.8 \%, 11.1 \%$ and $33.3 \%$ respectively. Corresponding to the longitudinal spacing of the steel springs $2.5 \mathrm{~m}, 1.875 \mathrm{~m}$, $1.25 \mathrm{~m}$ and $0.625 \mathrm{~m}$, it decreases by $25 \%, 33.3 \%$ and $50 \%$ respectively. So, compared to the stiffness decrease of the steel springs, the longitudinal spacing increase in the steel springs has more influence on the vertical vibration of the floating slab.

(a)

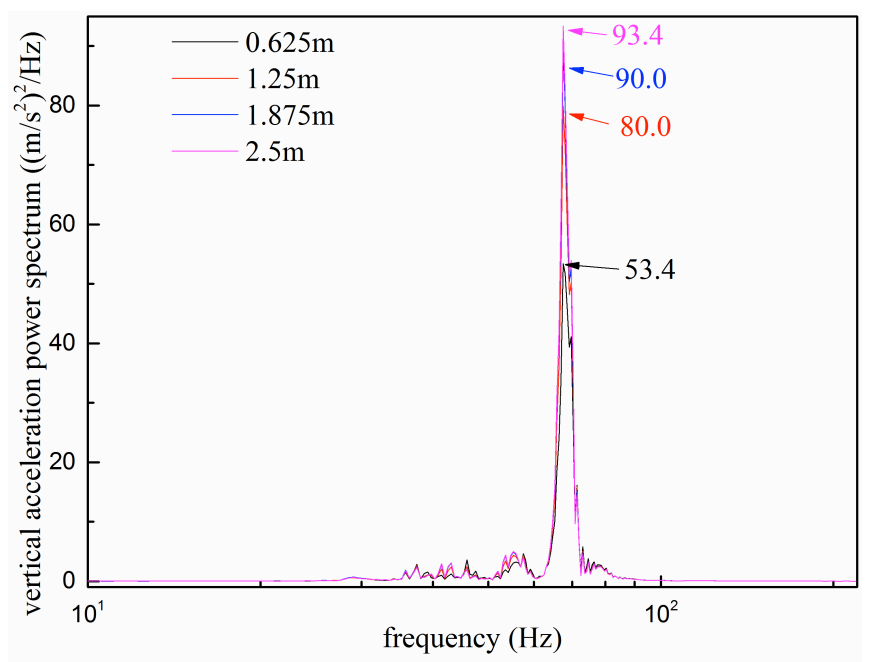

(b)

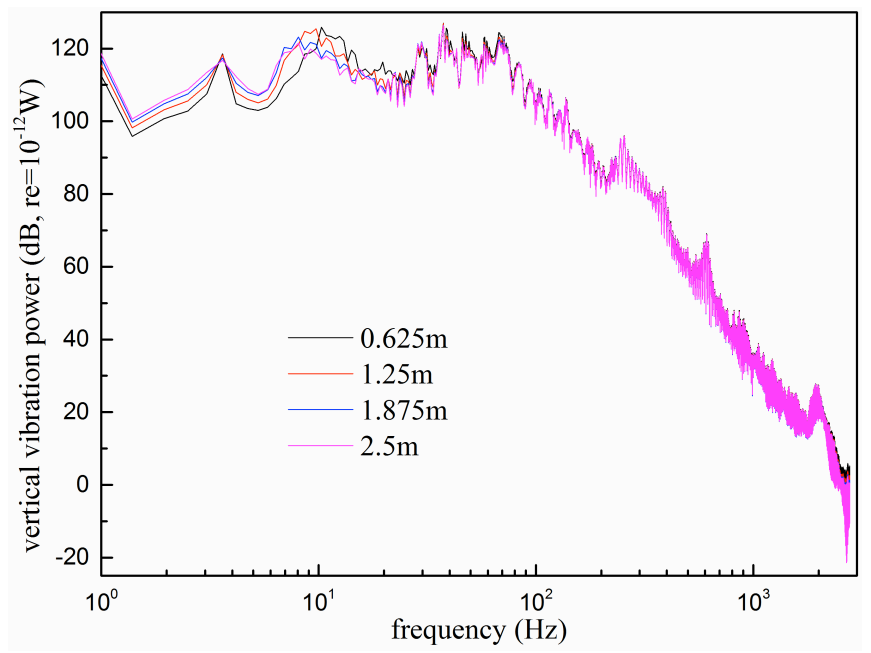

Fig. (6). The effect of longitudinal spacing of the steel springs on the vertical vibration of the floating slab.

The effects of the thickness of the floating slab on its vertical vibration are more complex, as shown in Fig. (7).

With the thickness of the floating slab increasing, the peaks of the vertical acceleration power spectrum of the floating slab at about $70 \mathrm{~Hz}$ become greater; however, as the thickness of the floating slab is $30 \mathrm{~cm}$, the vertical acceleration power spectrum of the floating slab reaches the maximum at about $50 \mathrm{~Hz}$. As the thickness of the floating slab is $15 \mathrm{~cm}$, the vertical acceleration power spectrum of the floating slab has a peak value at about $80 \mathrm{~Hz}$. 
(a)

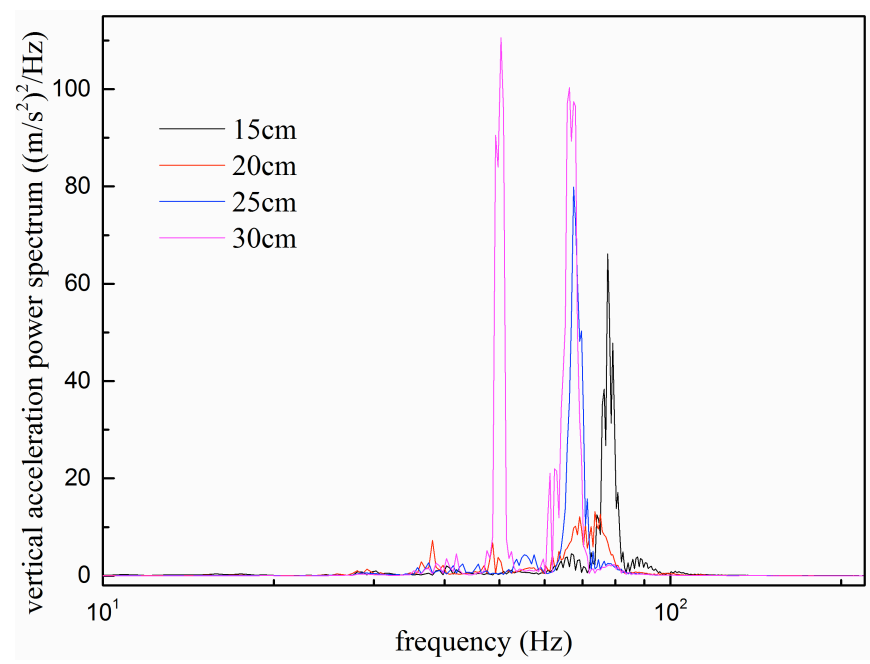

(b)

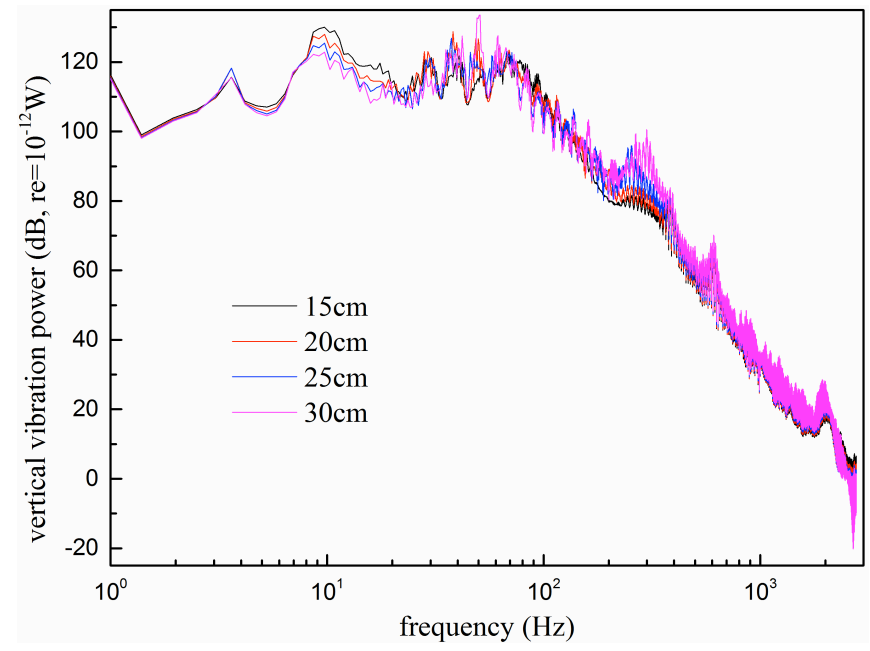

Fig. (7). The effect of thickness of the floating slab on its vertical vibration.

In the frequency ranges of $10 \sim 30 \mathrm{~Hz}$ and $200 \sim 400 \mathrm{~Hz}$, the thickness of the floating slab has obvious effects on the vertical vibration power of the floating slab. However, at other frequency ranges, the effects are very weak. In the frequency range of $10 \sim 30 \mathrm{~Hz}$, with the thickness of the floating slab increasing, the vertical vibration power of the floating slab is smaller. On the contrary, in the frequency range of $200 \sim 400 \mathrm{~Hz}$, with the thickness of the floating slab increasing, the vertical vibration power of the floating slab is greater.

\section{CONCLUSION}

The longitudinal spacing and the stiffness of the steel springs and the thickness of the floating slab have obvious effects on its vertical vibration in low frequency ranges below $200 \mathrm{~Hz}$. So, as we strive to reduce the vibration and noise radiation of the viaduct bridge in the future by changing the parameters of the floating slab, the disadvantages of the vibration and noise control of the floating slab have to be taken into consideration. In addition, the results are advantageous for conducting further researches on the control of the noise radiated by the floating slab.

\section{CONFLICT OF INTEREST}

The authors confirm that this article content has no conflict of interest.

\section{ACKNOWLEDGEMENTS}

The writers gratefully acknowledge the financial support provided by the National Natural Science Foundation of China (No.51165017).

\section{REFERENCES}

[1] J.T. Nelson, "Recent developments in ground-borne noise and vibration control", J. Sound Vib., vol. 193, no. 1, pp. 367-376, 1996.

[2] M.F.M. Hussein, and H.E.M. Hunt, "Modelling of floating-slab track with discontinuous slab, Part 1: response to oscillating moving loads", J. Low. Freq. Noise V. A., vol. 25, no. 1, pp. 23-39, 2006.

[3] M.F.M. Hussein, and H.E.M. Hunt, "Modelling of floating-slab track with discontinuous slab, Part 2: response to moving trains", J. Low. Freq. Noise V. A., vol. 25, no. 2, pp. 111-118, 2006.

[4] M.F.M. Hussein, and H.E.M. Hunt, "A numerical model for calculating vibration due to a harmonic moving load on a floatingslab track with discontinuous slabs in an underground railway tunne", J. Sound Vib., vol. 321, no. 1, pp. 363-374, 2009. 
[5] S. Gupta, and G. Degrande, "Modelling of continuous and discontinuous floating slab tracks in a tunnel using a periodic approach", J. Sound Vib., vol. 329, no. 8, pp. 1101-1125, 2010.

[6] F. Cui, and C.H. Chew, "The effectiveness of floating slab track system, Part I: receptance methods", Appl. Acoust., vol. 61, no. 4, pp. 441-453, 2000.

[7] Z.G. Li, and T.X. Wu, "Parametric excitation vibration of a floating slab track", J. Sound Vib. Shock, vol. 29, no. 2, pp. 17-20, 2010. (In Chinese)

[8] Z.G. Li, and T.X. Wu, "Study on the vibration isolation performance of floating slab track using dynamic receptance method", J. Vib. Eng., vol. 20, no. 3, pp. 207-212, 2007. (In Chinese).

[9] G. Lombaert, G. Degrande, B. Vanhauwere, B. Vandeborght, and S. Francois, "The control of ground-borne vibrations from railway traffic by means of continuous floating slabs", J. Sound Vib., vol. 297, no. 3, pp. 946-961, 2006.

[10] S.J. Cox, A. Wang, C. Morison, P. Carels, R. Kelly, and O.G. Bewes, "A test rig to investigate slab track structures for controlling ground vibration", J. Sound Vib., vol. 293, no. 3, pp. 901-909, 2006.
[11] L. Auersch, and Dr. Eng, "Dynamic behavior of slab tracks on homogeneous and layered soils and the reduction of ground vibration by floating slab tracks", J. Eng. Mech., vol. 138, no. 8, pp. 923-933, 2012.

[12] C.K. Hui, and C.F. Ng, "The effects of floating slab bending resonances on the vibration isolation of rail viaduct", Appl. Acoust., vol. 70, no. 6, pp. 830-844, 2009.

[13] L. Carlone, and D. J. Thompson, "Vibration of a rail coupled to a foundation beam through a series of discrete elastic supports", Institute of Sound and Vibration Research, University of Southampton, 2001.

[14] W.M. Zhai, "Vehicle-tack coupling dynamics", Beijing: Science press, 2007. (In Chinese)

[15] H.P. Liu, "A study on modeling, prediction and its control of wheel/rail rolling noises in high speed railway", $P h D$ thesis, Shanghai Jiaotong University, Shanghai, 2011. (In Chinese)

[16] S.L. Grassie, R.W. Gregory, D. Harrison, and K.L. Johnson, "The dynamic response of railway track to high frequency vertical excitation", J. Mech. Eng. Sci., vol. 24, pp. 77-90, 1982.

[17] J.H. Lin, W.S. Zhang, and F.W. Williams, "Pseudo-excitation algorithm for non-stationary random seismic response", Eng. Struct., vol. 16, pp. 270-276, 1994.

(C) Shi et al.; Licensee Bentham Open

This is an open access article licensed under the terms of the Creative Commons Attribution Non-Commercial License (http://creativecommons.org/licenses/ by-nc/4.0/) which permits unrestricted, non-commercial use, distribution and reproduction in any medium, provided the work is properly cited. 